\title{
Physicochemical changes of lead(II) contaminated sand-clay mixture
}

\author{
Saeid Nikkhah Nasab ${ }^{1}$ (D) Hamed Abdeh Keykha ${ }^{1}$ (D)
}

Received: 26 March 2020 / Accepted: 5 August 2020 / Published online: 19 August 2020

(c) Springer Nature Switzerland AG 2020

\begin{abstract}
In this study, the influence of lead nitrate as a hazardous environmental pollutant was studied through experimental tests to assess its physicochemical effects in soils. Artificially contaminated soil specimens were prepared using sand and two kinds of clays. Direct shear, consolidation, electrical resistivity and unconfined compression tests were conducted. In addition, the influence of lead cation on atterberg limits, $\mathrm{pH}$ and particle size distribution of soils was evaluated. Overall, the presence of lead ion in mixtures including bentonite increased the shear strength due to a flocculated structure and replacement of sodium cations by hydrogen ions which is along with the reduction of double-layer thickness. However, due to the broken bonds and rearranging of kaolinite particles to a weaker form, the strength of sand-kaolinite mixtures decreased with the increase of lead concentration. Based on the obtained results, with the addition of lead concentration, the compression index and electrical resistivity of all specimens decreased. Due to the acidic nature of positively charged lead cations, $\mathrm{pH}$ of the specimens directly affected and tended to a more acidic range. These findings indicate that the presence of lead ion improves the strength of some kinds of soils including bentonite and decreases the strength parameters of soils with kaolinite.
\end{abstract}

Keywords Contaminated soil · Shear strength · $\mathrm{pH}$ - Atterberg limits · Diffuse double layer · Electrical resistivity · Consolidation · Unconfined compression

\section{Introduction}

The growth of the world population and further demand for resources such as intact water and soil have motivated humanity to act on earth. However, these actions not only resolve the needs but it has caused some issues to the environment. Pollution is the most critical problem in the environmental sciences that must be highly attended [1]. Heavy metals such as lead, zinc, cadmium, mercury, and other types of heavy metals are well known for their influence on the soil engineered parameters and structures [2-4]. Such pollutants could also permeate within the soils by wastewater of industries which use such material in the production process. Although, nowadays, the remediation techniques are the main subject of interest and concern, knowing the impact of inorganics like heavy metal ions on soils could be beneficial to pick a suitable remediation technique. These contaminants are commonly found in several kinds of wastes and landfill leachates. Thus, on the geotechnical scope in which soil is the base material, the physicochemical reaction of heavy metal ions and soils should to be precisely evaluated.

Since, very limited studies have been conducted to investigate the effect of heavy metal ions on the soil shear strength and the other geotechnical parameters, this extent can be investigated more, to subtract the possible failures beneath of the structures and soil matrix as well [5]. With the increase of positively charged ions in soil solution, the shear strength of the kaolinite decreases due to the dissolution of the hydrogen bonds between the micelles $[6,7]$. Considering the bentonite subjected to the chemicals, the shear strength increases. This may be due

Saeid Nikkhah Nasab, saeid.nikkhah.nasab@gmail.com | 'Department of Civil Engineering, Buein Zahra Technical University, Buin Zahra, Qazvin, Iran. 
to the decrease of the diffuse double layer (DDL) thickness of contaminated bentonite which is along with the decrease of the dielectric constant of pore fluid. Chu et al. [5] concluded that the presence of heavy metals such as lead, zinc, and cadmium increases both the shear strength and the cohesion. They also carried out a series of electrical resistivity tests to determine how the heavy metals interact within the soil and found the electrical resistivity decreases with the increase of the heavy metal concentration. The higher the concentration of heavy metal, the higher changes in the soil properties are observed.

The presence of the chemicals such as heavy metal ions in soils causes some changes in atterberg limits [8-10]. This may be due to the changes in dielectric constant of the pore fluid [11]. According to the classic soil mechanics, the liquid limit (LL) of soils is mainly dependent on the adsorbed water molecules around the clay particles [11]. With the addition of the heavy metal ions, the liquid limit of kaolinite and bentonite increases and decreases, respectively $[6,12]$. However, changes in the atterberg limits (i.e. LL and PL) depend on the type of clay [13], ion concentration [8,9] and used chemical [10]. The clays with a higher LL have a thicker water film around the particles and, hence, any alteration in properties of the water layer, changes the clay behaviour. Li et al. [14] studied the behaviour of heavy metal contaminated soil with lead(II) cations and concluded that with the increase of the lead concentration, both the diffuse double layer (DDL) thickness and liquid limit decrease and there is a change in sedimentation behaviour of soil solution [15]. The heavy metal ion decreases the dielectric constant of the solution and the thickness of the DDL. Since the lead valence is double $(\mathrm{Pb}(\mathrm{II}))$, it has more influence on the $\mathrm{DDL}$ of the clay particles than the monovalent ions [16].

Addition of positively charged ions in soils decreases the $\mathrm{pH}$ of soil solution [17]. Acidity environments cause a denser distribution of positive charges on particle edges and decrease and increase the plastic properties (i.e. liquid limit and plastic limit) and the permeability, respectively [8]. Some laboratory experiments reported that in heavy metal contaminated clays, the adsorbed heavy metal ions on the clay surface cause a reduction in the $\mathrm{pH}$ of soil [17, 18]. In another word, the heavy metals cations in kaolinite compete with the hydrogen $\left(\mathrm{H}^{+}\right)$ions of the clay structure and exchange with the cations of the solution [17]. As a result, the shear strength decreases and particle arrangement changes to a flocculated structure and both the permeability and the compressibility increase. Palomino and Santamarina [19] showed that the presence of $\mathrm{NaCl}$ salt with varying concentrations can cause some alterations in clay behaviour, and it has a significant influence on sedimentation behaviour and the liquid limit. They also concluded that the kaolinite particles arrangement became somewhat disperse in the acidic environment. The lower the dielectric constant of the pore fluid, the higher the tendency of the particles to form a dispersed edge to face (EF) structure [6]. With a decrease of the dielectric constant of kaolinite solution, particles disperse and both the porosity and the compressibility increase. Laboratory results of Wahid et al. $[7,15]$ showed that despite the complex behaviour of kaolinite, particles solute on the edge sites in acidic environments and consequently the permeability increases.

Heavy metal contaminated soils have some changes in consolidation properties compared with uncontaminated samples. The higher the heavy metal ion concentration of pore fluid, the higher consolidation changes would occur. With the increase of the heavy metal ions in soil samples, the compression index decreases and the permeability increases [20]. These changes may be because of the particle rearrangement and changes of the atterberg limits and the $\mathrm{pH}$ [4].

The electrical resistivity (ER) test of soils is a rapid, costeffective and reliable test to discover the physicochemical reactions of pore fluids and clay surface. Some factors may change the electrical resistivity of soils such as the nature of the soil [21], degree of saturation [21,22], porosity [23], and temperature [22]. According to Archie's law [24], the electrical resistivity (ER) of soil increases with the increase of soil density which is along with a reduction in porosity. However, the application of Archie's equation is not suitable for clayey soils [25]. With the increase of pore fluid concentration the electrical resistivity decreases. Reactions between clay flakes and adsorbed water film facilitate the current to pass through the specimen and a lower voltage is required to be applied $[23,26]$.

Most of the previous studies on heavy metal contaminant-soil interaction have been carried out on clayey contaminated soils $[7,19,30]$. This study aims to investigate the effect of the physicochemical changes of sand-clay mixtures due to the presence of lead ion as a hazardous inorganic contaminant. Experimental studies were performed on two kinds of artificially lead-contaminated sand-clay mixtures (i.e. sand with kaolinite and bentonite, individually) to investigate the effect of lead concentration and the type of clay mineral on physicochemical properties of studied soils. For this purpose, a series of laboratory tests including direct shear, consolidation, electrical resistivity and unconfined compression tests were performed. In addition, the influence of lead ion on atterberg limits, $\mathrm{pH}$ and particle size distribution of soils was evaluated. Uncontaminated mixtures are also tested for comparison. 
Table 1 Physical properties of the used clay minerals

\begin{tabular}{lll}
\hline Type & Kaolinite & Bentonite \\
\hline Gs & 2.59 & 2.6 \\
LL (\%) & 38.8 & 180.2 \\
PL (\%) & 32.2 & 64.3 \\
PI (\%) & 6.8 & 115.9 \\
USCS & CL & CH \\
\hline
\end{tabular}

Table 2 Physical properties of the used sand

\begin{tabular}{ll}
\hline Parameter & Value \\
\hline Gs & 2.65 \\
Particle size $(\mathrm{mm})$ & 0.15 \\
Uniformity coefficient & 1.61 \\
Maximum dry density $\left.) \mathrm{kN} / \mathrm{m}^{3}\right)$ & 16 \\
USCS & $\mathrm{SP}$ \\
\hline
\end{tabular}

\section{Materials and methods used}

\subsection{Soil properties}

In this study, sand-clay mixtures are prepared using two manufactured clays (i.e. kaolinite and Na-bentonite) and uniform sand. The basic physical properties of used soils are listed in Tables 1 and 2. The industrial clays are kaolinite (classified as low plastic or CL based on ASTM D2487 [27]) and Na-bentonite (classified as high plastic or CH based on ASTM D2487 [27]) purchased from "Khak Chini Iran" and "Iran Barit", respectively. The used sand was purchased from "Tamin Maseh, Firouzkooh" factory with the commercial label of "Sand 161" and it is classified as poorly graded sand (SP) based on ASTM D2487 [27]. The used silica sand particles have a less chemical reaction with heavy metals due to having quartz and feldspar in its chemical property.

\subsection{Material and specimen preparation}

Since heavy metal ions cannot be found in high purity in nature and the preparation of the pure heavy metals is relatively difficult, the heavy metal salt combination is used. The used contaminant agent is lead nitrate salt $\left(\mathrm{Pb}\left(\mathrm{NO}_{3}\right)_{2}\right)$ and purchased from "Merck" company. Due to the high solubility of nitrate in water and its low activity with the clay minerals as well as sand particles, this combination of lead is selected [3]. The used bentonite is $\mathrm{Na}$-bentonite in which the sodium ions are the exchangeable ions in its structure. The sand-clay mixture is artificially contaminated in the specified concentrations of lead nitrate. Depending on the type and source of wastes, the leachates may have undesirable levels of concentration of contaminants. To prepare the artificially contaminated specimens, two specified concentrations (i.e.15,000 and 30,000 ppm) of the lead nitrate are selected for all specimens. The selected concentration levels of $\mathrm{Pb}$ contaminant are sometimes encountered at severely contaminated sites in urban or industrial areas as reported in previous studies $[3,4]$. The clay percentages of kaolinite in mixtures are $15,25,40$ and $60 \%$ by dry weight of the specimens and for bentonite, $15,20,40$ and $60 \%$ are chosen. To carry out the laboratory tests, first, the compaction tests are run on the mentioned mixtures and after that, the contaminated specimens are prepared at the same moisture content and maximum dry density of the uncontaminated mixtures to make an equal condition for all specimens. For instance, the optimum moisture content of sand-clay ( $25 \%$ of kaolinite) for the uncontaminated condition is around $13.5 \%$ and this moisture is used to prepare all the contaminated specimens (sand with $25 \%$ of kaolinite). After preparing the mixtures, they are labelled and incubated in plastic bags for 7 days of curing time. The cured specimens are left in the laboratory condition at room temperature $\left(25^{\circ} \mathrm{C}\right.$ centigrade) and a humidity of $95 \%$.

\subsection{Atterberg limits test}

Atterberg limits test is a basic and effective method to determine how the chemicals react with the clay particles. The contaminated and uncontaminated kaolinite and bentonite are individually tested as per ASTM D4318 [28]. Casagrande's apparatus is used to determine the liquid limit of the uncontaminated and the contaminated clays. Portions of the oven-dried clay minerals are soaked in the specified concentrations (i.e. $0,15,000,30,000 \mathrm{ppm}$ ) of lead nitrate for 7 days at the room temperature to ensure the completed reaction between soil and lead cations. After a week, the prepared clay pastes are put in the oven $\left(105^{\circ} \mathrm{C}\right)$ to be dried out before being tested.

\subsection{Compaction test}

Since the mixtures are prepared in the laboratory, it is necessary to determine the optimum moisture content (OMC) and the maximum dry density (MDD) of the sand-clay mixtures based on ASTM D698 [29]. To carry out the compaction experiment, the uncontaminated sand-clay mixtures (sand with different percentages of clay) are compacted in a mould with five equal layers and each layer is compacted using 25 uniform blows. This procedure is repeated in 5 different moisture contents to plot the compaction curves. 


\subsection{Direct shear test}

The specimens are compacted in three layers with thicknesses of $0.9,1.0$ and $1.1 \mathrm{~cm}$ (i.e. the first to the third layers) in a direct shear box $(10 \times 10 \mathrm{~cm})$ up to $95 \%$ of maximum dry density according to ASTM D3080 [30]. Some random scratches with a depth of maximum $2 \mathrm{~mm}$ are created on the first two compacted layers to create a uniform structure and also to obtain the results close to the reality [31]. The experiments are conducted in a strain controlled condition with a shear rate of $0.5 \mathrm{~mm} / \mathrm{min}$ for all the specimens to simulate a consolidated-drained condition. The specimens are sheared at three vertical stresses to plot the failure envelope. The vertical loads of 50, 100 and $200 \mathrm{kpa}$ on the apparatus hanger are chosen. These tests are repeated three times for each specimen to ensure the reliability of the obtained results and then the averages of them are reported.

\subsection{Consolidation test}

The one-dimensional consolidation test is performed on specimens with 40 and $60 \%$ clay minerals in the mixtures based on ASTM D2435-04 [32]. The specimens are saturated in deionised water (DIW) in the consolidation cell for $24 \mathrm{~h}$ before the test and then the loading procedure is continued until there is no significant settlement. The soil mixtures are compacted in a consolidation cell with a diameter of $5 \mathrm{~cm}$ and a height of $2 \mathrm{~cm}$.

\subsection{Unconfined compression test (UCT)}

The unconfined compression specimens are prepared in a $5 \mathrm{~cm}$ diameter and $10 \mathrm{~cm}$ height mould and compacted in 5 equal layers as per ASTM D2166-00 [33]. After 7 days of curing in the plastic bags, the specimens are tested. During compaction of the specimens, the $2 \mathrm{~mm}$ scratches are also created on surfaces of the first four compacted layers to make a uniform structure between layers.

\subsection{Particle size analysis using the hydrometer}

In previous researches, the influence of the heavy metal contaminants on the particle size is reported $[7,14]$. The determination of the grain size distribution of clay particles and the changes after contamination is carried out based on ASTM D421-85 [34]. Furthermore, to investigate the sedimentation behaviour of particles, both the uncontaminated and the contaminated suspensions are tested [35]. To run the sedimentary test, $50 \mathrm{~g}$ of grounded soil (contaminated and uncontaminated, individually) is put into a $250 \mathrm{~mL}$ glass jar and its volume is increased to $250 \mathrm{~mL}$ with deionised water (DIW). After stirring the solutions for nearly 2 minutes, they are kept unshaken for $24 \mathrm{~h}$ to allow the particles to sediment naturally.

\section{$2.9 \mathrm{pH}$ measurement}

To know how acidic or basic a soil solution is, the $\mathrm{pH}$ measurement is used based on ASTM D4972-01 [36]. Soil pH is measured in a 1:2 soil:water solution ratio agitated for almost one minute by a Milwaukee Mi151 pH meter. Then, the prepared solutions are remained unshaken for $16 \mathrm{~h}$ to complete the reactions between soil and the heavy metal ions. The probe of the $\mathrm{pH}$ device is then cleaned and put in the soil solutions to record the $\mathrm{pH}$.

\subsection{Electrical resistivity test}

The electrical resistivity (ER) experiment is conducted based on ASTM G187-18 [37] using two electrodes to measure the potential differences. The specimens are compacted in a box of $10 \times 15 \times 5 \mathrm{~cm}$ in width, length and depth and saturated with deionised water (DIW). A known DC, with a voltage of $12 \mathrm{~V}$, is applied between the two graphite electrodes mounted on the opposite faces of the box. Then, voltage drops between the two pins inserted in the specimen in a specified distance from the graphite electrodes (i.e. $5 \mathrm{~cm}$ ) are recorded. It is noteworthy that the specimens are prepared in the maximum dry density and the optimum moisture content of the uncontaminated mixtures. Lead nitrate is artificially added to the specimens in the mentioned concentrations (i.e. 15,000 and $30,000 \mathrm{ppm}$ ) and the results are compared with the uncontaminated specimens.

\section{Results and discussion}

\subsection{Optimum moisture content}

Figure 1 shows the obtained results of the compaction test for the uncontaminated specimens. The standard proctor compaction tests were carried out on the mixtures with the kaolinite in the percentages of 15 and $25 \%$ by dry weight of each specimen and 15 and $20 \%$ based on dry weight of specimens for bentonite in mixtures, separately. The obtained results of the optimum moisture content were used in the specimen preparation for the direct shear, the electrical resistivity, the consolidation and the unconfined compression tests in the wet tamping (WT) method [31]. The consolidation test is used for clayey soils mostly. Thus, for this purpose, the two other clay contents of 40 and $60 \%$ based on the dry weight of the specimens were selected. As seen in Fig. 1, the increase of plastic particle contents decreases the maximum dry density while the 

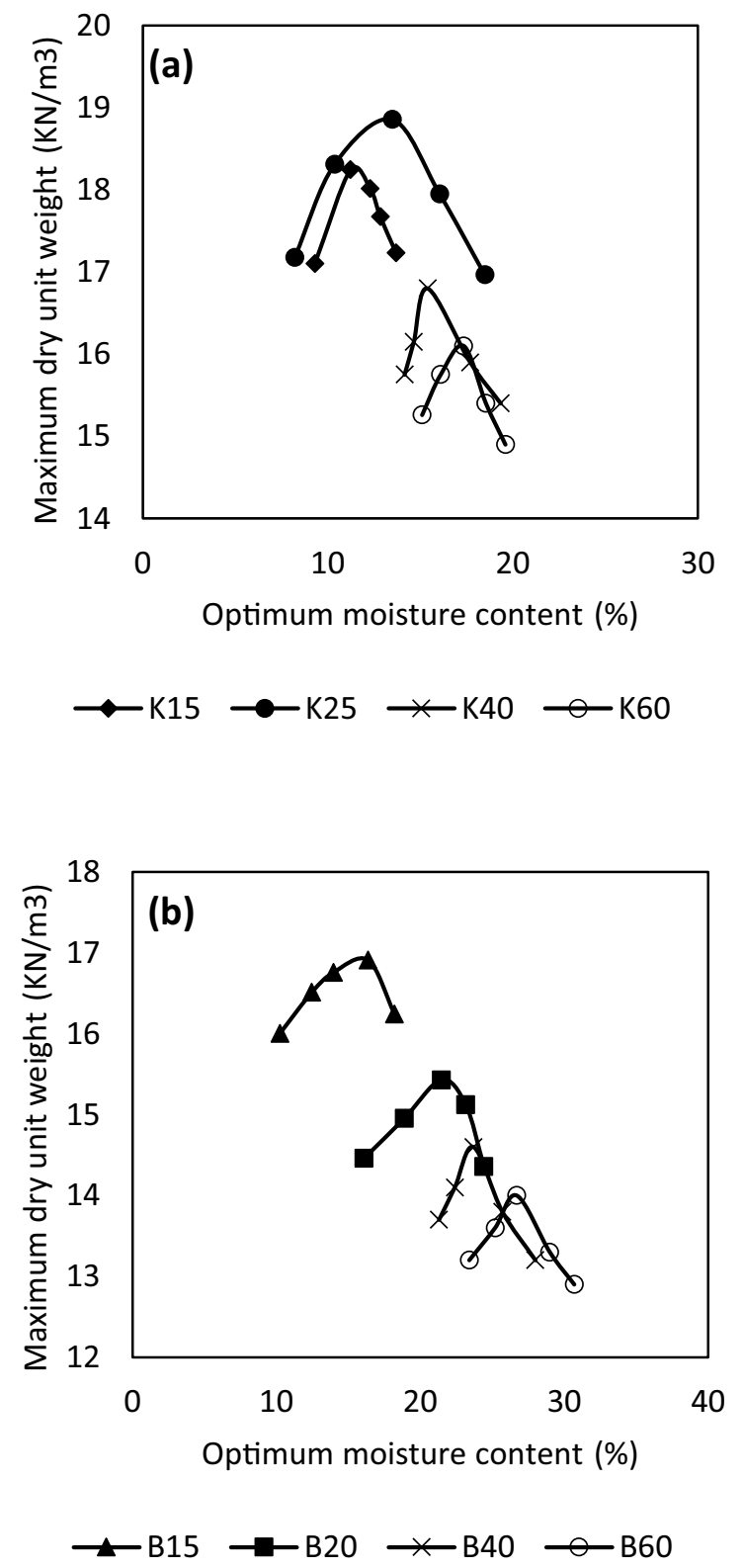

Fig. 1 Compaction curves of sand with the different contents of a kaolinite and $\mathbf{b}$ bentonite minerals

moisture content shifts to the right side of the curve. This may be due to the fact that the pores in soil are filled with a higher amount of clay particles and in addition, sand particles are covered with higher percentages of clay particles. Thus, the curve shift makes a more plastic behaviour of the mixtures [11].

\subsection{Effect of lead(II) cations on atterberg limits}

The obtained results of the atterberg limits for pure contaminated and uncontaminated kaolinite and bentonite are listed in Table 3. The kaolinite minerals tend to have
Table 3 Atterberg limits

\begin{tabular}{lllll}
\hline Atterberg limits & \multicolumn{3}{l}{ Lead nitrate concentration (ppm) } \\
\cline { 3 - 5 } & & 0 & 15,000 & 30,000 \\
\hline LL (\%) & K & 38.8 & 40.4 & 41.6 \\
& B & 180.2 & 102.3 & 82.3 \\
PL (\%) & K & 32 & 33.3 & 34.1 \\
& B & 64.3 & 48.9 & 46.6 \\
PI (\%) & K & 6.8 & 7.1 & 7.5 \\
& B & 115.9 & 53.4 & 35.7 \\
\hline
\end{tabular}

low plasticity behaviour and have a low absorption capacity due to the strong hydrogen linkage between particles and low cation exchange capacity (CEC) [6]. The results showed there is no significant change in the atterberg limits of kaolinite contaminated by the lead cations compared to the uncontaminated specimens. This is due to the less dependency of kaolinite to the thickness of double-layer (DDL). In contrast, tangible changes in the contaminated bentonite were observed. There was a significant decrease in the LL of the contaminated bentonite for $30,000 \mathrm{ppm}$ compared to the uncontaminated pastes. This is due to the reduction of the double-layer water thickness that is along with the lower dielectric constant of the pore fluid [14, 16]. Hence, in contrast with the kaolinite, the Na-bentonite showed a dependency on its double-layer (DDL) changes. Whereas, for kaolinite, the main factor is the hydrogen linkage between constituent elements and its $\mathrm{pH}$-dependant behaviour [38]. This reason mostly takes part in the kaolinite chemical reactions. The results of the atterberg limits are presented in Fig. 2 for both kaolinite and bentonite minerals.

\subsection{Influence of the lead(II) cations on sedimentation behaviour}

Sedimentation experiment is an empirical test in which the settling behaviour, as well as the height of sedimented particles, could be tested. Figure 3 shows the sedimentation behaviour of both kaolinite and bentonite before and after the contamination. In this experiment, the maximum concentration (i.e. 30,000 ppm) for lead nitrate was selected. As expected, the kaolinite had a flocculated structure before being contaminated and had a lower deposit height, whereas, with the addition of the lead cations, the height of the deposit somewhat increased. This means there is a slightly dispersed structure with the addition of lead(II). In another word, the kaolinite structure changed to an edge to face (EF) from edge to edge (EE) as reported by other researchers [39]. However, the particles have a flocculated structure, but in the edge to face $(E F)$ structure, pore fluid is more allowed to penetrate 


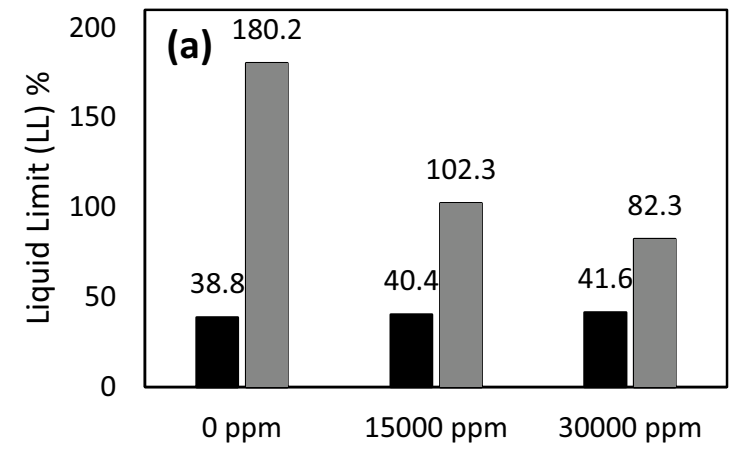

$\square \mathrm{K} \square \mathrm{B}$
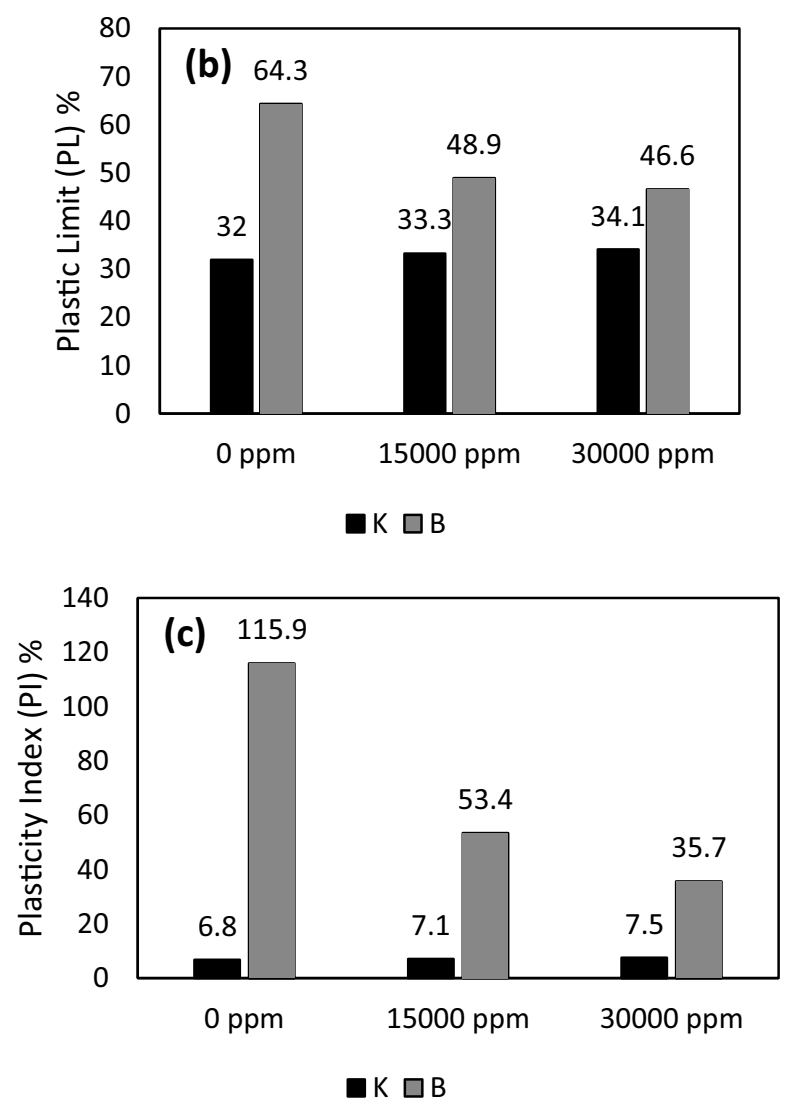

Fig. 2 a Liquid limit, b plastic limit and c plasticity index of the uncontaminated and the contaminated clay minerals with the different lead concentrations $(0,15,000$ and $30,000 \mathrm{ppm})$

into the clay layers space [12]. In contrast to this, there was an adverse behaviour for bentonite. Although the uncontaminated bentonite is completely dispersed with no settling behaviour, the lead(II) contaminated bentonite had a lower deposit height and showed a flocculated structure with a rapid settling time. Briefly, the contaminated bentonite settled with a higher sedimentation rate and kaolinite had a relatively constant height [40].

Owing to the specific characteristics of clays, both kaolinite and bentonite react differently with chemicals.

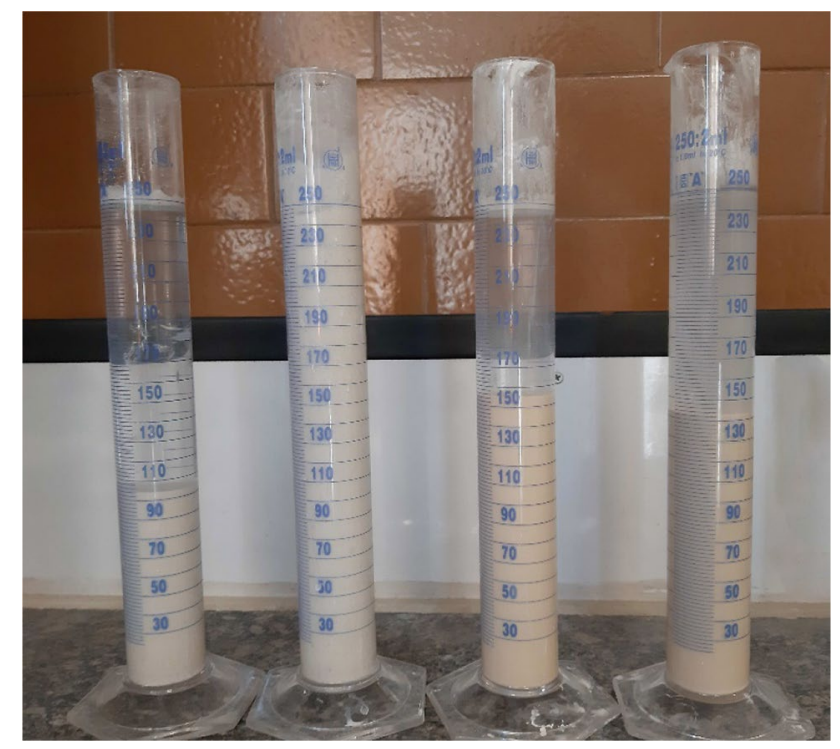

Fig. 3 Sedimentation experiments of contaminated bentonite, uncontaminated bentonite, contaminated kaolinite and uncontaminated kaolinite (left to right, respectively)

The reaction of the Na-bentonite with the contaminants is highly dependent on DDL thickness around the particles, yet, as discussed above, in kaolinite, the influence of organic and inorganic chemicals is mostly dominated by the hydrogen bond strength [41]. Because of the unnoticeable rule of the DDL in kaolinite, there must be a discussion on the strong hydrogen bond between particles to explain the changes induced by the addition of the chemicals [3]. However, in some researches, it is reported that the kaolinite is a $\mathrm{pH}$-dependant mineral that its reactions with heavy metal ions depend on the $\mathrm{pH}$ of the solution [42].

\subsection{Influence of lead(II) cations on the grain size distribution}

According to Fig. $4 a$ and $b$ the artificially contaminated kaolinite tends to have a silty structure and bentonite significantly tends to settle rapidly with the addition of the lead nitrate concentration in solution. With the presence of the lead cations in the solution, there is a shift in kaolinite hydrometer curve to a weaker edge to face (EF) flocculated structure and consequently, the penetration of the cations within the space of the constitutive layers is facilitated. Generally, the higher the concentration of the lead cations, the higher the tendency of the kaolinite flakes to a weaker structure. With the addition of the heavy metal electrolyte solution the DDL thickness of bentonite. This behaviour makes a more interlocked and flocculated structure that increases the porosity compared to the uncontaminated soils $[7,12,15,16]$. 


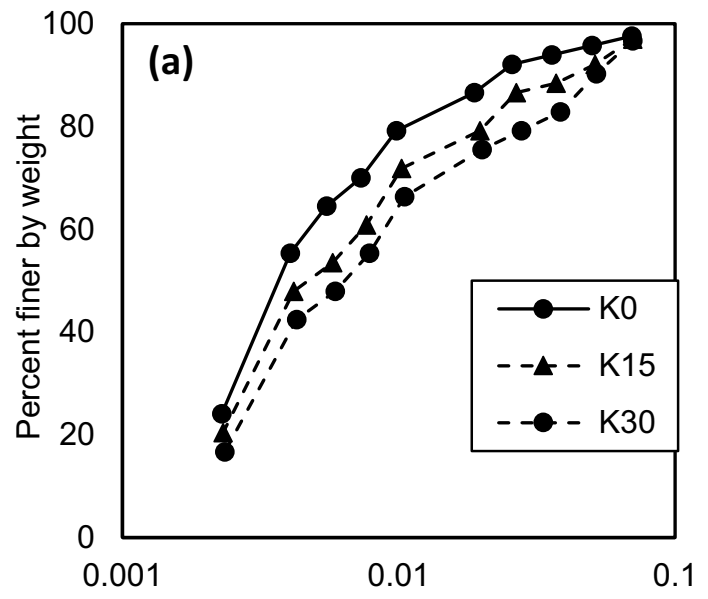

Grain size (mm)

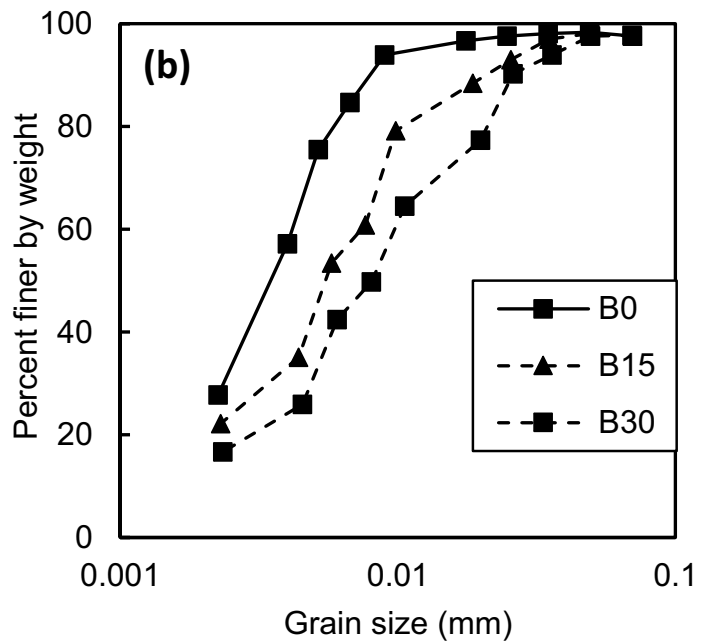

Fig. 4 Hydrometer test results of the uncontaminated and the contaminated $\mathbf{a}$ kaolinite and $\mathbf{b}$ bentonite with the different lead concentrations $(0,15,000$ and $30,000 \mathrm{ppm})$

The lead cations cause a particle rearrangement up to a specified concentration (i.e. threshold concentration) and the further addition of the cations would not have a significant effect. This is due to the occupation of the surface sites by cations and a flocculated structure $[5,15]$. Figure 5 shows that the clay contents of the lead contaminated clays become less.

\subsection{Effect of the lead(II) cations on the pH}

The $\mathrm{pH}$ results of the lead(II) contaminated and the uncontaminated clays are illustrated in Fig. 6. Regarding the obtained results, the lead cations caused a pH reduction of the soil. The dissolved positively charged lead ions caused an acidic environment which was also reported in literature $[8,18]$. The hydrogen ions $\left(\mathrm{H}^{+}\right)$released in

\section{Clay Content (\%)}

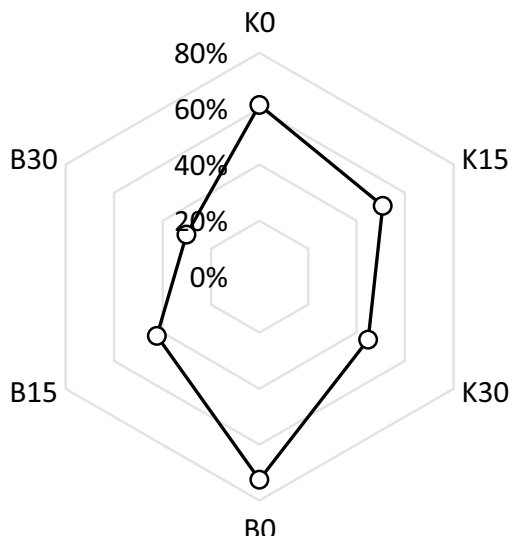

Fig. 5 The clay contents of the uncontaminated and the contaminated clay minerals with the different lead concentrations $(0$, 15,000 and $30,000 \mathrm{ppm}$ )

the soil solution is due to the hydrolysis reaction of the lead cations into the soil and then, alumina and silicate constituents transformed to another compounds and dissipated into the solution. Due to the cation exchange process and increase of the $\mathrm{H}^{+}$ions, the $\mathrm{pH}$ decreased. In this research, once the sand-clay mixtures were used and then pure clays were tested to know if there are considerable differences between these two. The results showed that the sand in the mixture did not show any significant influence on the $\mathrm{pH}$ of the contaminated soils. This may be due to the low activity of the sand particles which are electrically neutral in contrast to the negatively charged clays. Moreover, the quartz and feldspar of the used sand do not have a noticeable reaction with the chemicals [43].

According to the results from Fig. 6, as expected, the lead cation electrolyte solution decreased the $\mathrm{pH}$ of both

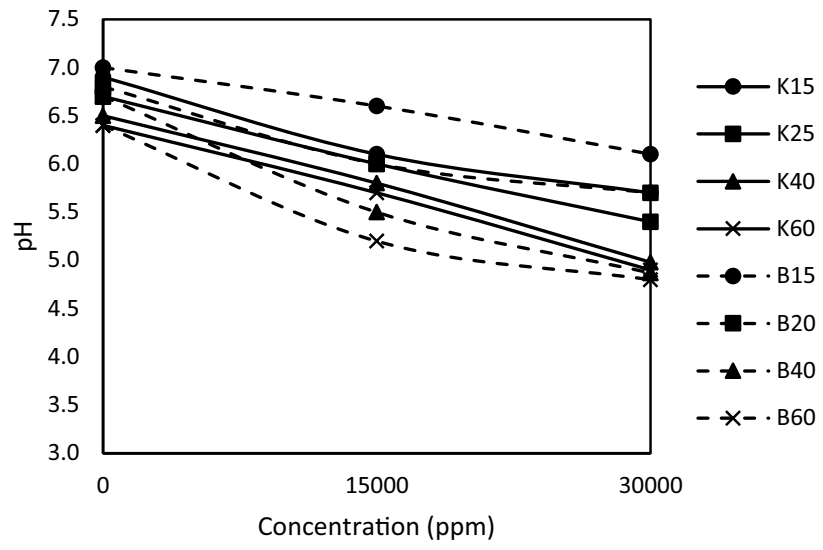

Fig. 6 The $\mathrm{pH}$ of the uncontaminated and the contaminated specimens with the different clay contents 
the sand-kaolinite and the sand-bentonite specimens. The $\mathrm{pH}$ reduction of the sand-bentonite mixtures was lower than the sand-kaolinite mixtures owing to the higher buffer capacity of pure bentonite clays compared to kaolinite in an uncontaminated manner. The presence of sodium ions in the bentonite structure is a reason to have a higher negative charge than kaolinite clays [17]. In an acidic condition induced by the solution of the lead nitrate salt, the $\mathrm{pH}$ decreases and in consequence, more rounded particles forms. According to the theorem of Sposito [44], the double-layer model introduced by Gouy-Chapman [16] cannot explain the differences between adsorption of the chemicals with equal valence and thus, it is essential to establish a new adsorption mechanism to justify the experimental observations. The newly introduced mechanism is also related to the water film adsorbed around the particles defined as inner-sphere and outer-sphere complexes as shown in Fig. 7.

The difference between these two complexes is that there is an adsorbed water layer between the cations and the clay surfaces. In the inner-sphere complexes, the ions chemically adsorb to the particle surfaces and there is no water molecule in between. Due to the chemical linkage between the ions and the clay surface, the inner-sphere complexes bonds are stronger than the outer-sphere complexes [38]. According to the results of Goldberg et al. [45], the inner-sphere complexes mainly occur in acidified environments at a $\mathrm{pH}$ range of around $4-5$. Moreover, increasing of the anions in the solution that is along with the increase of $\mathrm{pH}$, would change the inner-sphere complexes to the outer-sphere complexes. The outer-sphere adsorption could cause a slight change of particle arrangement owing to the adsorbed water film between surface and cation. The inner-sphere adsorption could also change the

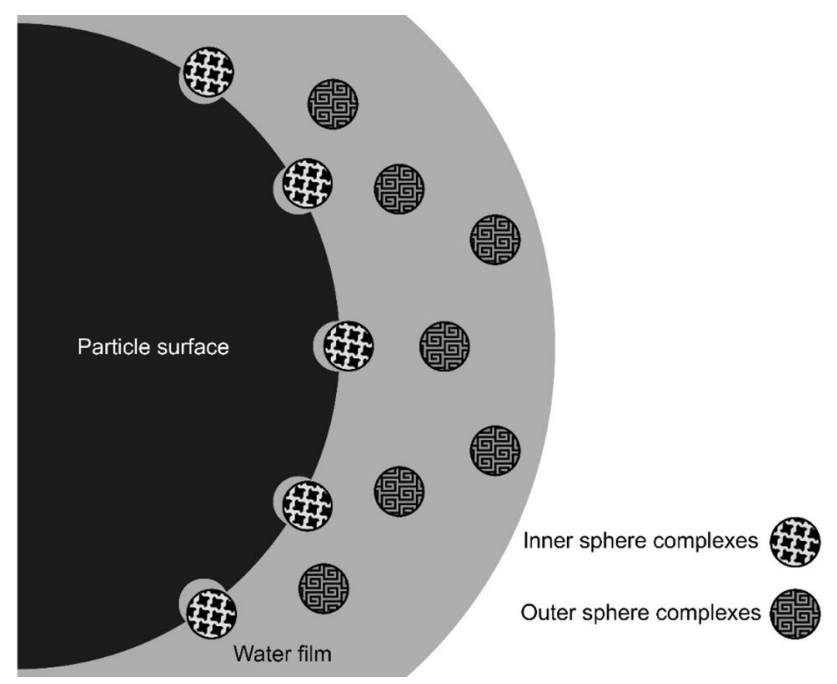

Fig. 7 Adsorption complexes mechanisms particle structure with a reduction in the diffuse double layer thickness $[7,11]$. However, the depiction of both the inner-sphere and outer-sphere mechanisms needs further scientific investigations and equipments.

\subsection{Shear strength of the lead(II) contaminated soil}

The direct shear tests were carried out on the specimens after 7 curing days in laboratory conditions. According to Fig. 7, the shear strength of the sand-kaolinite mixtures reduced with the addition of clay mineral from 15 to $25 \%$. The increase of the kaolinite percentage caused a somehow cohesion and less particle contacting. As can be seen in Fig. 8a, the sand-kaolinite contaminated specimens, show a reduction in the shear strength while the sand-bentonite mixtures show an increase in the shear strength according to Fig. $8 \mathrm{~b}$. This procedure is more affected with the increase of the lead(II) concentration until there is a threshold in which the strength does not considerably change afterwards.

As mentioned earlier, the bond between the flakes is a factor that plays a significant role in kaolinite after subjecting to the positively charged lead cations. In another word, the linkage between the particles in the uncontaminated specimens is stronger than the contaminated mixtures. Therefore, the shear strength decreased in the contaminated kaolinite clay. On the other side, the lead cations increased the shear strength of the contaminated sand-bentonite specimens owing to the reason related to the double-layer around the fine particles. It is proved that the bentonite particles are less dominated by their van der Waals forces but the double-layer thickness changes are more effective [6]. The reduction in the strength of the contaminated specimens is shown in Fig. 8a. This is due to the weakening of the bonds between clay micelles when they are imposed to the lead cations.

In the kaolinite, the adsorbed water molecules can hardly penetrate through the 1:1 kaolinite structure. The lead(II) cations have a larger ionic radius $(1.19 \mathrm{~nm})$ than the hydrogen ions $(0.300 \mathrm{~nm})$. The larger ionic radii apply a sudden stress to the particles and change the strength and the structure $[15,46]$.

There are a few kinds of research on studying the behaviour of the contaminated sand with heavy metals ions. The utilised sand in the present study is a standard and pure type of sand that has been formed basically with quartz and feldspar in its structure. Thus, the sand particles carry the least electrical charge and have the least reaction with the lead cations and other chemicals. When the concentration reaches a threshold, the sand particles are expected to be destructed. Hence, it is more likely that the sand particles take part in the chemical reactions with the heavy metal ions and therefore, the 

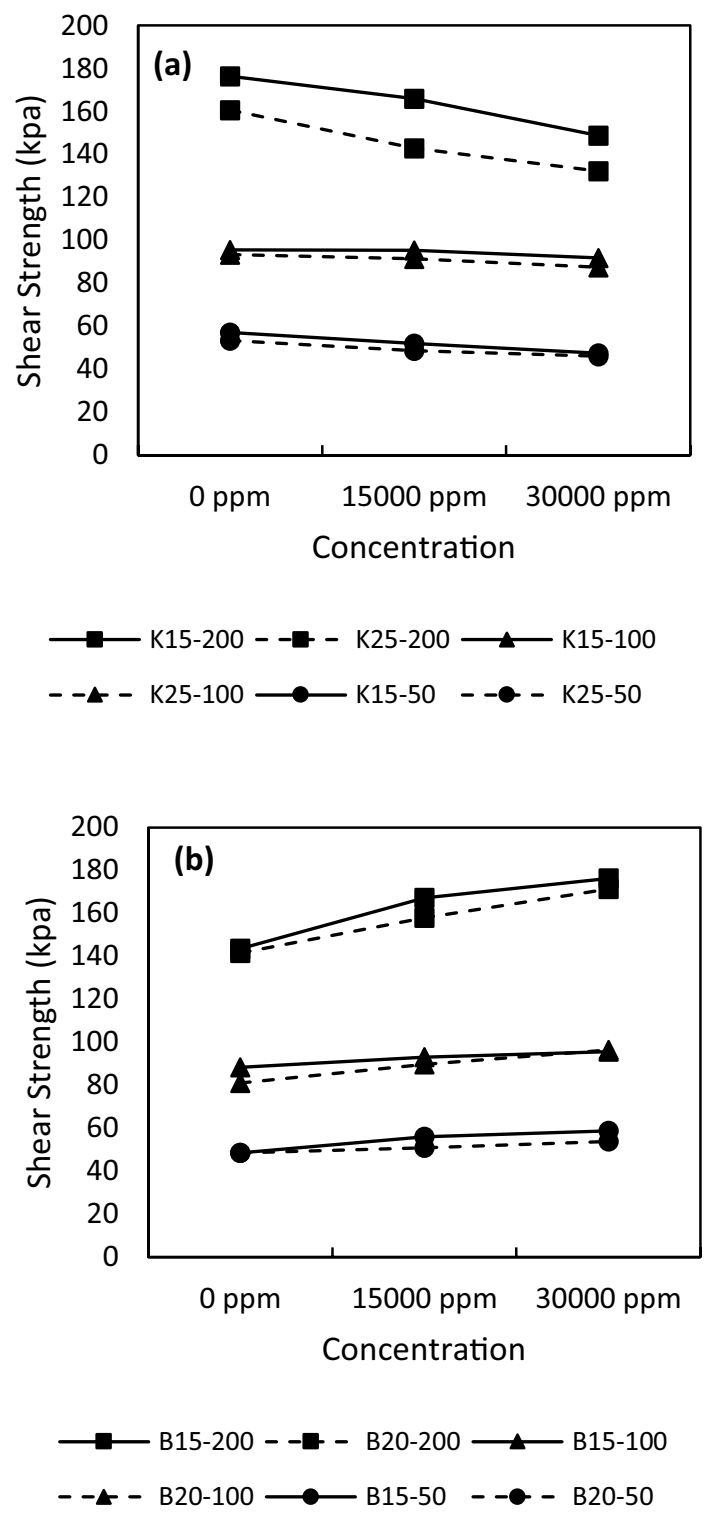

Fig. 8 The peak strength of the sand with a 15 and $25 \%$ of kaolinite and b 15 and $20 \%$ of bentonite under various vertical loads $(50,100$ and $200 \mathrm{kPa}$ )

particle shapes would change to a rounder edge shape with grooves on surfaces [47]. However, this phenomenon is not considered in the present study since the concentration of cations is not such high.

Figure 9 shows the failure envelope of the sand with 15 and $25 \%$ of kaolinite, respectively. With the increase of the clay content, a reduction of about $10 \%$ in the shear strength of the uncontaminated mixtures was observed. The contaminated specimens $(15,000$ and $30,000 \mathrm{ppm})$ also showed a reduction of about 14 and $13 \%$ in the shear strength, respectively for the sand mixtures with the $25 \%$ of kaolinite compared to the $15 \%$ of kaolinite.
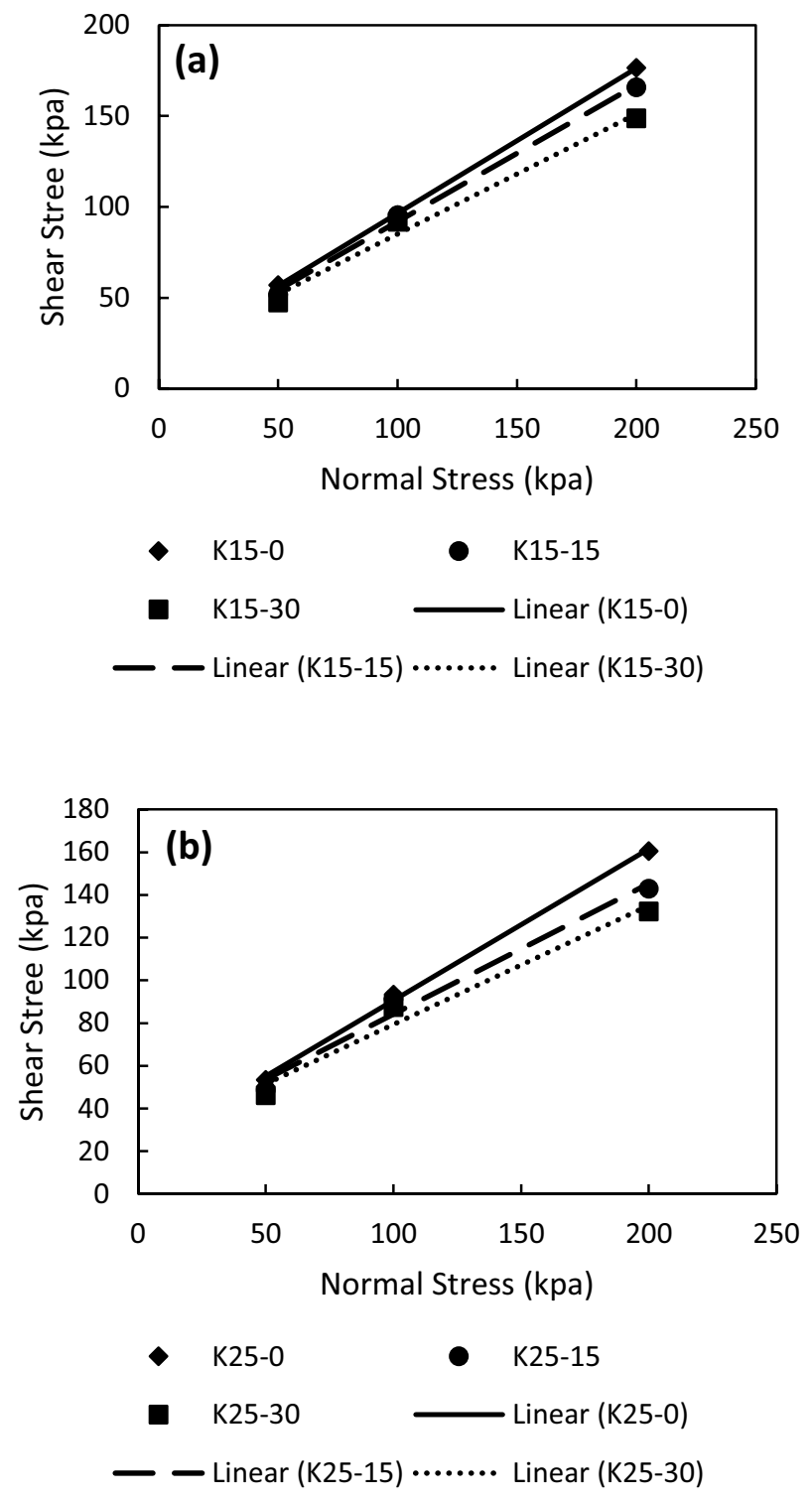

Fig. 9 Failure envelop of the sand with a $15 \%$ and b $25 \%$ of the kaolinite (uncontaminated and contaminated) with the different lead concentrations $(0,15,000$ and $30,000 \mathrm{ppm})$

As shown in Fig. 10, there is an increase in the shear strength of sand-bentonite mixtures with the increase of the lead(II) cations. The addition of the heavy metal electrolyte causes a reduction of the dielectric constant of pore fluid. Thus, the higher the salt valence and concentration, the higher the DDL suppression occurs. The strength of the mixture with $15 \%$ of bentonite in both the concentrations of 15,000 and 30,000 ppm increased about 14 and $18 \%$, respectively. Increasing the clay content of the mixture to $20 \%$, caused an increase of about 13 and $18 \%$ for both concentrations of 15,000 and $30,000 \mathrm{ppm}$, respectively. In addition, the uncontaminated sand-kaolinite mixtures showed dilative behaviour. With the addition of the 

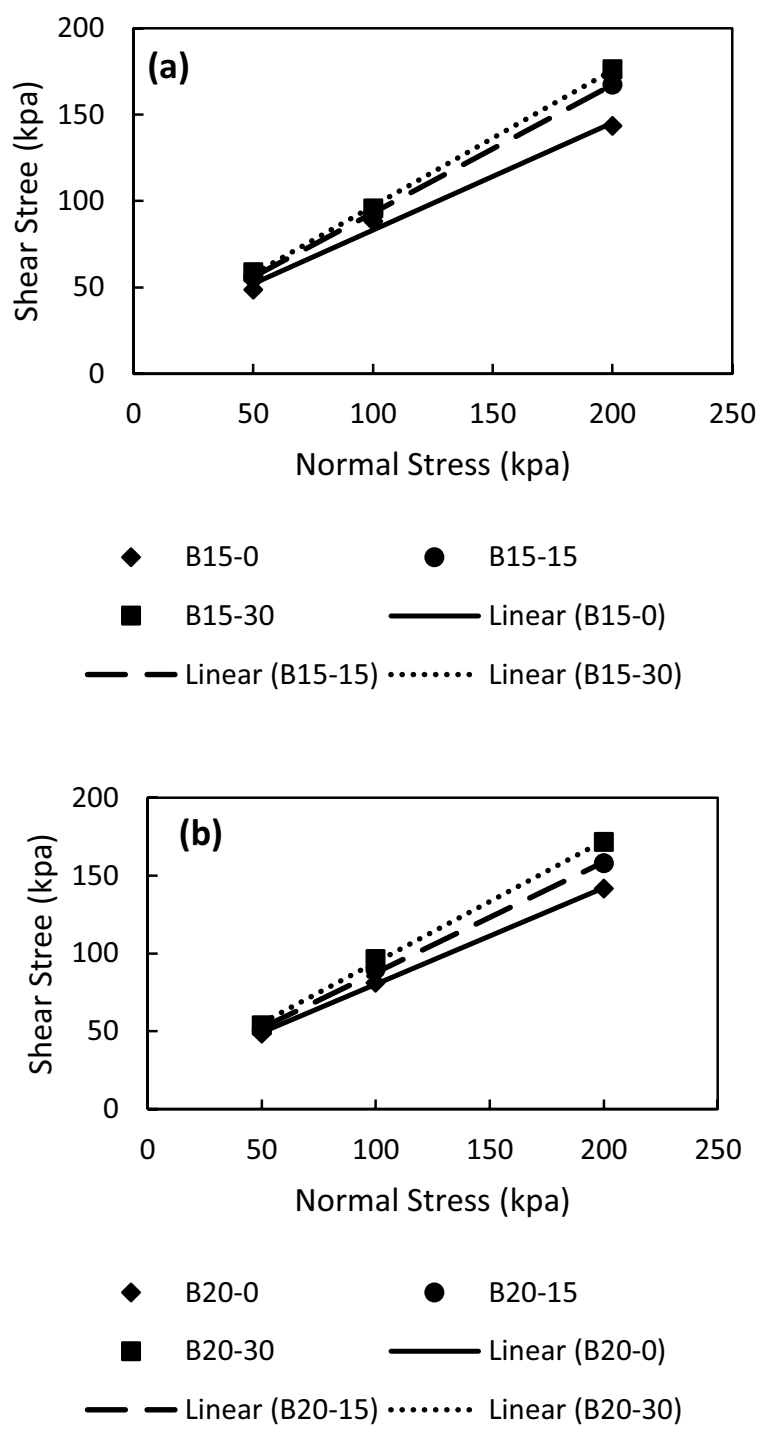

Fig. 10 Failure envelop of the sand with a $15 \%$ and b $20 \%$ of the bentonite (uncontaminated and contaminated) with the different lead concentrations $(0,15,000$ and $30,000 \mathrm{ppm})$

contaminant, a transition to a contractive behaviour was observed in the sand-kaolinite contaminated mixtures. An adverse response was observed for the bentonite including mixtures which is due to the flocculated structure of the contaminated that causes a more particle interlocking during shear $[6,15,16]$.

According to Fig. $11 \mathrm{a}$, an increase of the lead concentration to 15,000 and $30,000 \mathrm{ppm}$ in the sand with $15 \%$ of kaolinite caused a reduction in the internal friction angle of about 8 and $17 \%$ compared to the uncontaminated specimens, respectively. The results of the cohesion strength showed an increase of about 3 and $15 \%$ for specimens with 15,000 and 30,000 ppm concentrations, respectively. In the specimens with $25 \%$ of kaolinite, a reduction of about 13 and $24 \%$ for the friction angle was (a) Sand $+15 \%$ Kaolinite

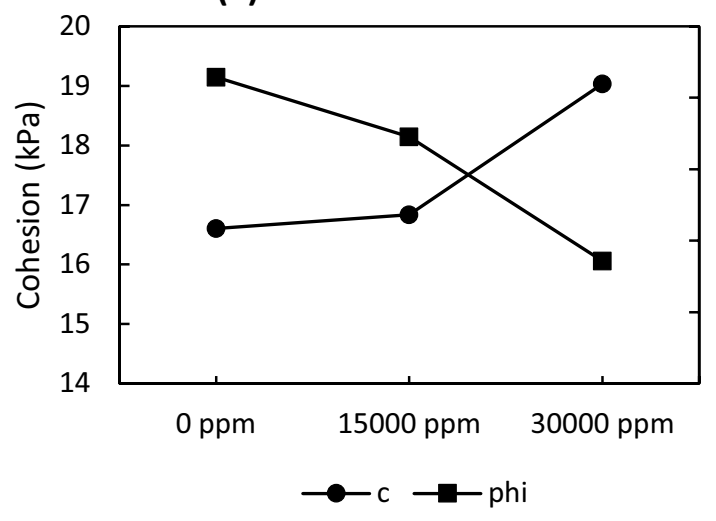

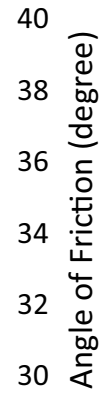

(b) Sand $+25 \%$ Kaolinite

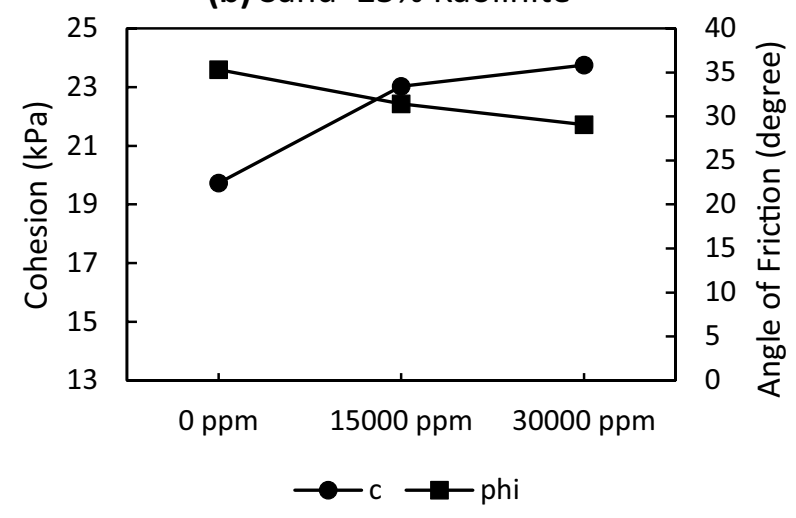

Fig. 11 Effect of lead cations on shear strength parameters of sand with a $15 \%$ and $\mathbf{b} 25 \%$ of kaolinite

observed as shown in Fig. 11 b. Furthermore, the cohesion of the contaminated specimens ( 15,000 and $30,000 \mathrm{ppm})$ increased by 17 and $21 \%$, respectively.

As discussed earlier, because of the lower specific surface area of the kaolinite than the bentonite, the behavioural changes of the kaolinite minerals are less dependent on DDL. The significant factors which play basic roles in the kaolinite are the $\mathrm{pH}$ and the dielectric constant changes of the solutions. In the acidic environment of the lead nitrate salt, alumina and silicate of the kaolinite dissolve, and the edge sites break down [48].

The internal friction angle of the sand with $15 \%$ of the bentonite increased by 15 and $21 \%$ for 15,000 and $30,000 \mathrm{ppm}$ concentrations, respectively. It can also be seen from Fig. 12a, that the cohesion of the sand with $15 \%$ of the bentonite decreased by 12 and $15 \%$ compared to the uncontaminated specimens. With the addition of $20 \%$ of the bentonite in specimens, the internal friction angle increased by 12 and $20 \%$ for 15,000 and 30,000 ppm concentrations, respectively (Fig. 12b). The cohesion -that is a factor for contractive behaviour- decreased by about 11 
(a) Sand $+15 \%$ Bentonite

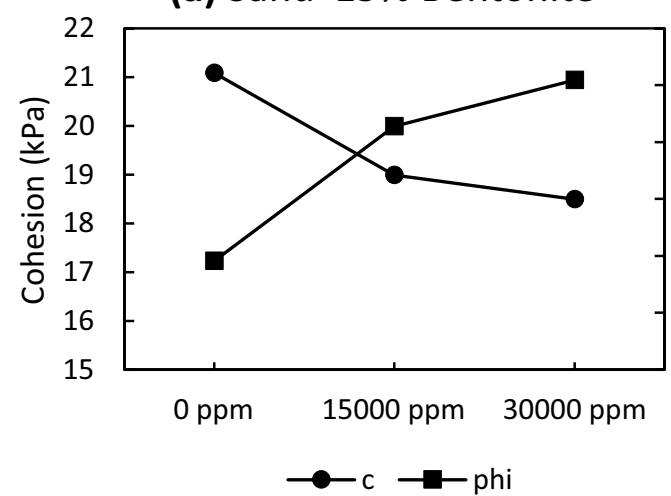

(b) Sand $+20 \%$ Bentonite

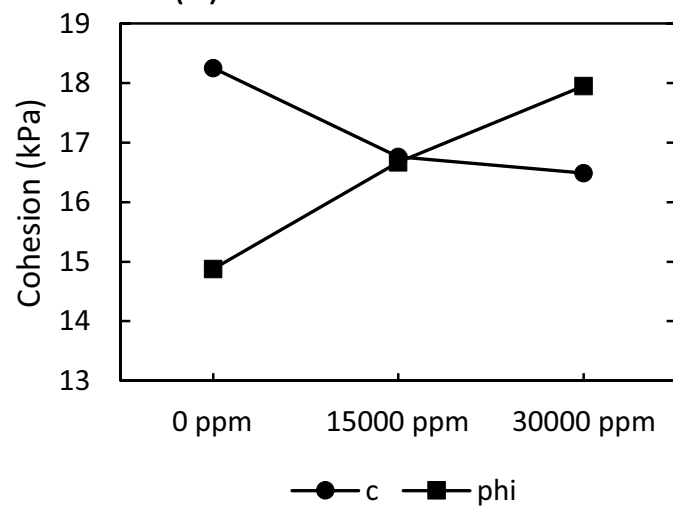

40

38

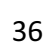

36

34

32

30

$28 \stackrel{\text { 年 }}{\stackrel{4}{4}}$

Fig. 12 Effect of lead cations on shear strength parameters of sand with a $15 \%$ and $\mathbf{b} 20 \%$ of bentonite

and $16 \%$ for the sand with $20 \%$ of the bentonite compared to the uncontaminated mixtures.

\subsection{Influence of the lead(II) cations on consolidation properties}

The carried out consolidation tests results on the sand specimens with 40 and $60 \%$ of the kaolinite and the bentonite are presented in Figs. 13 and 15. In this series of experiments, the maximum cation concentration $(30,000 \mathrm{ppm})$ was used. The consolidation tests results indicate that the adsorption of the lead ions on the kaolinite basal surfaces causes a reduction in the compression index $\left(C_{C}\right)$ of about $14 \%$ as shown in Fig. 14. This is in a good accordance with the results obtained from the $\mathrm{pH}$ measurement, atterberg limits, direct shear tests and the other researchers work results. As presented in Fig. 13 , the sand with the $40 \%$ of the kaolinite has a slightly higher porosity than the sand with the $60 \%$ of the kaolinite based on the fact that the sand particles are less surrounded by the clay flakes and can be easily compacted. The spaces between the clay constituents are somewhat open and

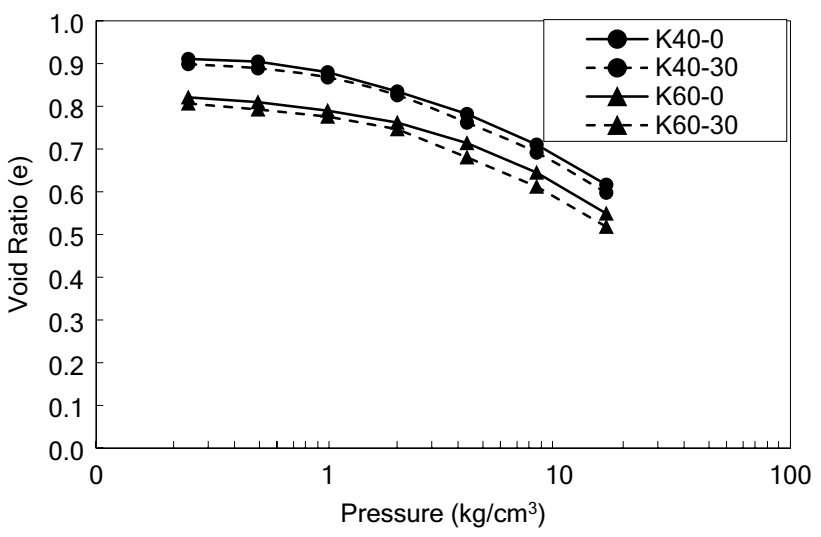

Fig. 13 e-log(p) of the sand with 40 and $60 \%$ of the kaolinite with the different lead concentrations ( 0 and 30,000 ppm)

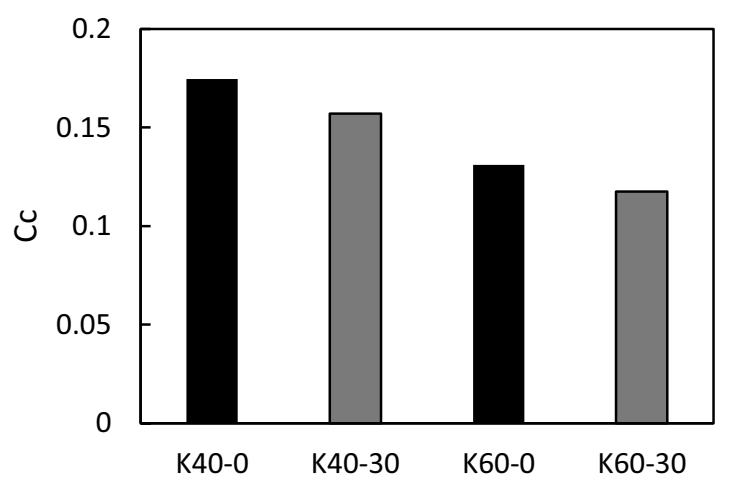

Fig. 14 Compression index of the sand with 40 and $60 \%$ of the kaolinite with the different lead concentrations ( 0 and 30,000 ppm)

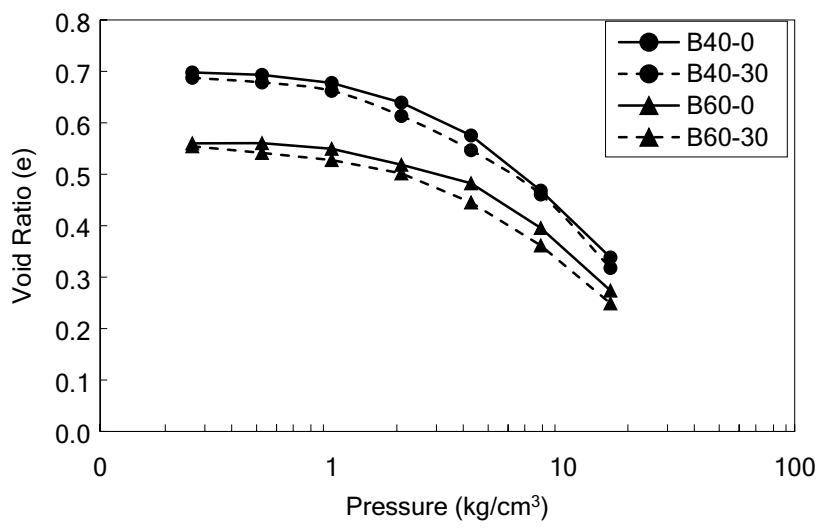

Fig. 15 e- $\log (p)$ of the sand with 40 and $60 \%$ of the bentonite with the different lead concentrations ( 0 and 30,000 ppm)

allow a more cation exchange process in the microstructure [15]. The obtained results from the sand mixtures with 40 and $60 \%$ of the bentonite are shown in Figs. 15 and 16. 


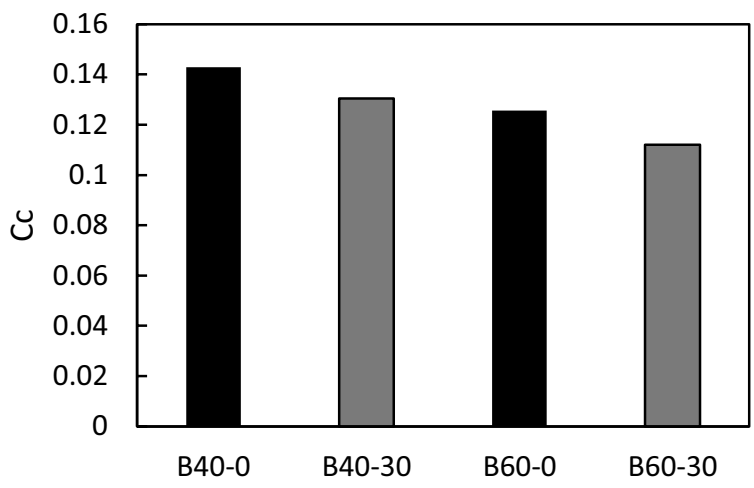

Fig. 16 Compression index of the sand with 40 and $60 \%$ of the bentonite with the different lead concentrations ( 0 and $30,000 \mathrm{ppm}$ )

The compression index $\left(C_{C}\right)$ for the sand-bentonite mixtures decreased by $11 \%$ averagely.

\subsection{Effect of the lead(II) contamination on permeability}

The unavoidable leakage of the landfills leachate is one of the most important factors which must be considered in the landfill design. According to the consolidation test results presented in the previous section, the permeability of the sand mixtures for both the kaolinite and bentonite increases with the increase of the lead cations concentration in the solution. The increase of the permeability was not obvious in some applied pressures and that is a reason for the complex behaviour of the kaolinite exposed to the chemicals. In other words, the adsorption of the heavy metal cations on the clay surfaces causes some chemical changes in the mineral itself and the exchanging of the contaminants with larger ionic radii than hydrogen (i.e. addition of lead ions) creates a rearranged structure. Due to the cation exchange procedure, more water molecules could penetrate within the clay interlayer space. The obvious reason for the permeability reduction might be because of the pore-clogging associated with the rearrangement of the particles [15].

According to the results presented in Table 4, the permeability of the contaminated sand-clay mixtures increased due to the particle rearrangement. The data were extracted using Terzaghi's method to obtain the permeability coefficient using the consolidation results [11].

\subsection{Influence of the lead(II) cations on unconfined compression strength}

A series of the unconfined compression strength tests (UCT) was carried out on the sand specimens with the 40
Table 4 Permeability of mixtures with varying concentrations

\begin{tabular}{lll}
\hline $\begin{array}{l}\text { Perme- } \\
\text { ability } \\
(\mathrm{m} / \mathrm{s})\end{array}$ & \multicolumn{2}{l}{$\begin{array}{l}\text { Lead nitrate con- } \\
\text { centration }(\mathrm{ppm})\end{array}$} \\
\cline { 2 - 3 } & 0 & 30,000 \\
\hline $\mathrm{K} 40$ & $2.66 \mathrm{E}-08$ & $3.51 \mathrm{E}-08$ \\
$\mathrm{~K} 60$ & $2.03 \mathrm{E}-08$ & $2.12 \mathrm{E}-08$ \\
$\mathrm{~B} 40$ & $2.08 \mathrm{E}-08$ & $2.29 \mathrm{E}-08$ \\
$\mathrm{~B} 60$ & $1.87 \mathrm{E}-08$ & $2.31 \mathrm{E}-08$ \\
\hline
\end{tabular}

and $60 \%$ of the kaolinite and the bentonite, individually, on both the contaminated (i.e. 15,000 and 30,000 ppm) and the uncontaminated specimens. The results of the UCT are presented in Fig. 17. As shown, the UCT of the sand-kaolinite lead(II) contaminated specimens decreased by 9 and 36\% approximately for the concentrations of 15,000 and $30,000 \mathrm{ppm}$ for the sand with $40 \%$ of the kaolinite, respectively. A reduction of the UCT was observed in the sand with $60 \%$ of the kaolinite of about 38 and $73 \%$ for the 15,000 and 30,000 ppm of the contamination, respectively. In contrast, there was an increase in the UCT for the contaminated sand-bentonite specimens. For the mixtures with $40 \%$ of bentonite, there was an increase of 14 and $31 \%$ for the 15,000 and 30,000 ppm concentrations, respectively. The UCT curves peak points of the sand with $60 \%$ of bentonite also increased by 8 and $25 \%$ for the contaminated specimens in the concentrations of the 15,000 and 30,000 ppm, respectively.

\subsection{Influence of the lead(II) cations on electrical resistivity}

Flowing of the electricity throughout soils is highly dependent on saturation degree, type of soil and its chemical properties. A current was applied to the compacted sand-clay mixtures through two graphite electrodes and the voltage drop was determined between the two points within the sand-clay mixture. While the particles adsorb water molecules, the measured potential drops across the two inner pins increases. Soil particles cannot convey the current solely. The water molecules are known as an electrical conductor. With the addition of the heavy metal concentration, the amount of the adsorbed water around the particles decreases and thus, the electrical conductivity (EC) and the electrical resistivity (ER) increases and decreases, respectively [22, 24].

As shown in Fig. 18a, for the specimens with the $40 \%$ of the kaolinite there is a reduction in electrical resistivity of 12.5 and $18 \%$ with the 15,000 and 30,000 ppm of the lead(II) contamination, respectively. The reduction of the electrical resistivity for the specimens with $60 \%$ of the kaolinite for the same concentrations (i.e. 15,000 and $30,000 \mathrm{ppm}$ ) is correspondingly about $15 \%$ and 

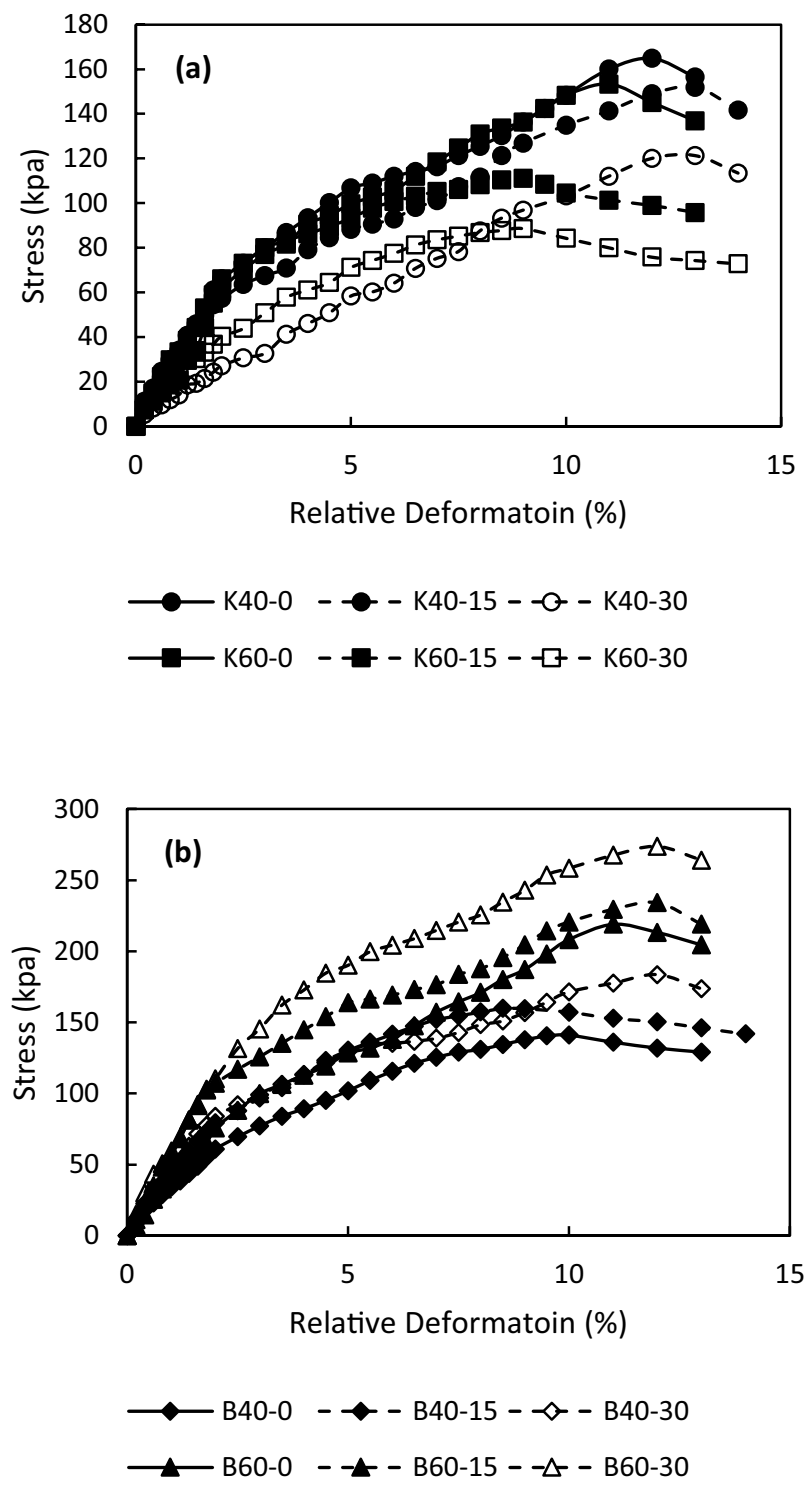

Fig. 17 The UCT of the uncontaminated and the contaminated sand mixtures with various $\mathbf{a}$ kaolinite and $\mathbf{b}$ bentonite contents and the different lead concentrations ( $0,15,000$ and 30,000 ppm)

$20 \%$. Furthermore, a reduction in the electrical resistivity was observed about 18 to $27 \%$ for the sand-bentonite specimens (Fig. 18b) that follow the results of other researchers $[5,22,23]$. This may be due to the ion exchange process on the clay surfaces. The higher the ion valence, the more conductive clay surfaces. However, the reduction of the electrical resistivity appears to reach a threshold in which there would be no significant alteration in the electrical resistivity afterwards $[23,26]$.
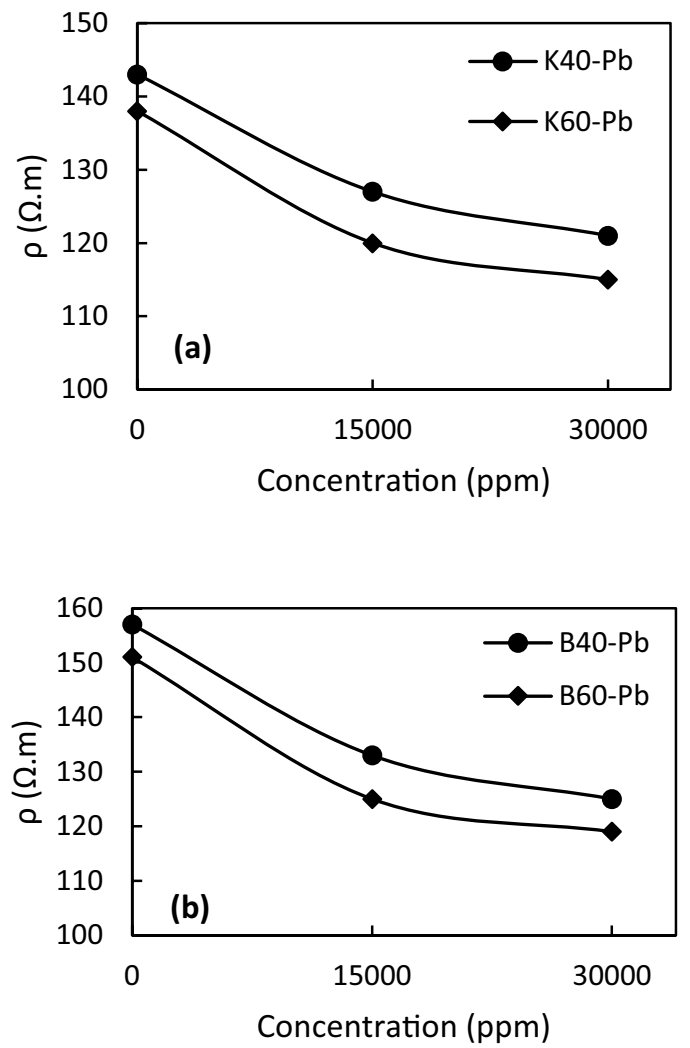

Fig. 18 The electrical resistivity of the sand mixtures with various contents of $\mathbf{a}$ kaolinite and $\mathbf{b}$ bentonite

\section{Conclusion}

In this study, the effect of the lead cations was investigated on the sand-clay mixtures. Since the different levels of contamination could occur in severe conditions, two concentrations (i.e. 15,000 and 30,000 ppm) of the lead nitrate salt and two types of clay mineral with varying percentages (i.e. kaolinite and Na-bentonite) were chosen to prepare the artificially contaminated mixtures. Based on the findings, the atterberg limits (i.e. liquid limit and plastic limit) of the lead contaminated kaolinite and $\mathrm{Na}$ bentonite slightly increased and significantly decreased, respectively. Moreover, the sedimentation behaviour of kaolinite was somewhat unchanged. Although, for $\mathrm{Na}-$ bentonite, a rapid settlement occurred. The addition of the lead cations decreased the $\mathrm{pH}$ of soil solutions due to the release of the hydrogen ions within the solution. According to the results, the shear strength of the contaminated mixtures with different percentages of the two types of clay minerals (i.e. kaolinite and bentonite) decreased and increased, respectively. The increase of the cohesion for the sand with $15 \%$ of the kaolinite was about 6 and $16 \%$ in the concentrations from 15,000 to 30,000 ppm, correspondingly. The strength of the contaminated sand 
mixtures with $25 \%$ of the kaolinite decreased to $19 \%$ in the maximum level of concentration, and, the friction angle decreased by 14 and $24 \%$ in the concentrations of 15,000 and $30,000 \mathrm{ppm}$, respectively. For the sand-bentonite mixtures, with the increase of the heavy metal concentration, a more interlocked structure formed. The shear strength of the sand with 15 and $20 \%$ of the bentonite increased by about 17 and $20 \%$ compared to the uncontaminated specimens, respectively. The consolidation test results showed a reduction in the compression index $\left(C_{C}\right)$ by averagely $14 \%$ with the increase of the lead concentration in both the sand-kaolinite and sand-bentonite specimens. The unconfined compression of the contaminated specimens decreased and increased in specimens with the kaolinite and bentonite, respectively. There was also a tendency to decrease of the electrical resistivity (ER) with the increase of the heavy metal cations concentration in the all specimens. This study was conducted on laboratory prepared specimens to simulate the field condition and findings of the present work can be extended to field practices as a rule of thumb. Authors recommend a further study on single or multi heavy metal contaminated soils for a better understanding of soil-chemical interactions and also remediation techniques.

\section{Compliance with ethical standards}

Conflict of interest The authors declare that they have no conflict of interest.

\section{References}

1. Nivedya K (2019) Study on the effect of pH on the atterberg limits of kaolinitic and montmorillonitic clay. In: Lecture notes in civil engineering. Springer, pp 251-256

2. Chu Y, Liu S, Cai G, Bian H, Zhang T (2016) Physical and microscopic characteristics experiments with heavy metal polluted cohesive soil. In: Geotechnical special publication. American Society of Civil Engineers (ASCE), pp 42-52

3. Du YJ, Jiang NJ, Liu SY, Jin F, Singh DN, Puppala AJ (2014) Engineering properties and microstructural characteristics of cement-stabilized zinc-contaminated kaolin. Can Geotech J 51:289-302. https://doi.org/10.1139/cgj-2013-0177

4. Jiang NJ, Du YJ, Liu SY, Zhu JJ (2014) Experimental investigation of the compressibility behaviour of cement-solidified/stabilised zinc-contaminated kaolin clay. Geotech Lett 4:27-32. https:// doi.org/10.1680/geolett.13.00079

5. Chu Y, Liu S, Wang F, Cai G, Bian H (2017) Estimation of heavy metal-contaminated soils' mechanical characteristics using electrical resistivity. Environ Sci Pollut Res 24:13561-13575. https:// doi.org/10.1007/s11356-017-8718-x

6. Muththalib A, Baudet BA (2019) Effect of heavy metal contamination on the plasticity of kaolin-bentonite clay mixtures and an illite-smectite rich natural clay. E3S web of conferences, vol 92. https://doi.org/10.1051/e3sconf/20199210005
7. Wahid AS, Gajo A, di Maggio R (2011) Chemo-mechanical effects in kaolinite. Part 2: exposed samples and chemical and phase analyses. Geotechnique 61:449-457. https://doi. org/10.1680/geot.8.P.068

8. Spagnoli G, Fernández-Steeger T, Feinendegen M, Azzam R, Stanjek H (2011) Influence of the dielectric constant, electrolyte concentration and $\mathrm{pH}$ of the pore fluids on the shear strength of monomineralic clays. Ital Geotech J 58(3):11-24

9. Dutta J, Mishra AK (2015) A study on the influence of inorganic salts on the behaviour of compacted bentonites. Appl Clay Sci 116-117:85-92. https://doi.org/10.1016/j.clay.2015.08.018

10. Calvello M, Lasco M, Vassallo R, Di Maio C (2005) Compressibility and residual shear strength of smectitic clays: influence of pore aqueous solutions and organic solvents. Ital Geotech J 1(2005):34-46

11. Mitchell JK, Soga K (2005) Fundamentals of soil behavior. Wiley, Hoboken

12. Yong $R$ (2000) Geoenvironmental engineering: contaminated soils, pollutant fate, and mitigation. CRC Press, Boca Raton

13. Schmitz RM, Schroeder C, Charlier R (2004) Chemo-mechanical interactions in clay: a correlation between clay mineralogy and atterberg limits. Appl Clay Sci. https://doi.org/10.1016/j. clay.2003.12.015

14. Li J, Xue Q, Wang P, Li Z (2015) Effect of lead (II) on the mechanical behavior and microstructure development of a Chinese clay. Appl Clay Sci 105-106:192-199. https://doi. org/10.1016/j.clay.2014.12.030

15. Wahid AS, Gajo A, Di Maggio R (2011) Chemo-mechanical effects in kaolinite. Part 1: prepared samples. Geotechnique 61:439-447. https://doi.org/10.1680/geot.8.P.067

16. Chapman DL (1913) LI. A contribution to the theory of electrocapillarity. Lond Edinb Dublin Philos Mag J Sci 25:475-481. https://doi.org/10.1080/14786440408634187

17. Yong RN, Phadungchewit $Y$ (1993) $\mathrm{pH}$ influence on selectivity and retention of heavy metals in some clay soils. Can Geotech J 30:821-833. https://doi.org/10.1139/t93-073

18. Miranda-Trevino JC, Coles CA (2003) Kaolinite properties, structure and influence of metal retention on $\mathrm{pH}$. Appl Clay Sci 23:133-139. https://doi.org/10.1016/S0169-1317(03)00095 $-4$

19. Palomino AM, Santamarina JC (2005) Fabric map for kaolinite: effects of $\mathrm{pH}$ and ionic concentration on behavior. Clays Clay Miner 53:211-223. https://doi.org/10.1346/CCMN.2005.05303 02

20. Dutta J, Mishra AK (2017) Consolidation behavior of compacted bentonites in the presence of heavy metals. J Hazard Toxic Radioact Waste. https://doi.org/10.1061/(ASCE)HZ.2153-5515.00003 56

21. Datsios ZG, Mikropoulos PN, Karakousis I (2017) Laboratory characterization and modeling of DC electrical resistivity of sandy soil with variable water resistivity and content. IEEE Trans Dielectr Electr Insul 24:3063-3072. https://doi.org/10.1109/ TDEI.2017.006583

22. Abu-Hassanein ZS, Benson CH, Blotz LR (1996) Electrical resistivity of compacted clays. J Geotech Eng 122:397-406. https://doi. org/10.1061/(asce)0733-9410(1996)122:5(397)

23. Kibria G, Hossain S (2017) Electrical resistivity of compacted clay minerals. Environ Geotech 6:18-25. https://doi.org/10.1680/ jenge.16.00005

24. Archie GE (1942) The electrical resistivity log as an aid in determining some reservoir characteristics. Soc Petrol Eng. https:// doi.org/10.2118/942054-G

25. Choo H, Song J, Lee W, Lee C (2016) Impact of pore water conductivity and porosity on the electrical conductivity of kaolinite. Acta Geotech 11:1419-1429. https://doi.org/10.1007/s1144 0-016-0490-4 
26. Cardoso R, Dias AS (2017) Study of the electrical resistivity of compacted kaolin based on water potential. Eng Geol 226:1-11. https://doi.org/10.1016/j.enggeo.2017.04.007

27. ASTM D2487-17 (2017) Standard practice for classification of soils for engineering purposes (unified soil classification system), ASTM International, West Conshohocken, PA, 2017. www. astm.org

28. ASTM D4318, ASTM D 4318-10, D4318-05 A (2005) Standard test methods for liquid limit, plastic limit, and plasticity index of soils. Report 04:1-14. https://doi.org/10.1520/D4318-10

29. ASTM International (2003) Standard test methods for laboratory compaction characteristics of soil using. ASTM Standards Guide, vol 3, pp 1-10. https://doi.org/10.1520/D1557-12.1

30. ASTM D3080/D3080M-11 (2011) Standard Test Method for Direct Shear Test of Soils Under Consolidated Drained Conditions (Withdrawn 2020), ASTM International, West Conshohocken, PA. https://www.astm.org

31. Selig E, Ladd R (1978) Preparing test specimens using undercompaction. Geotech Test J 1:16. https://doi.org/10.1520/gtj10 $364 j$

32. ASTM D 2435/D2435M-11 (2011) Standard test methods for one-dimensional consolidation properties of soils using incremental loading. ASTM International, West Conshohocken, pp 1-9. https://doi.org/10.1520/D1883-07E02.dry

33. ASTM (2013) Standard test method for unconfined compressive strength of cohesive soil 1. ASTM International, pp 1-7. https:// doi.org/10.1520/D2166

34. ASTM:D421-85 (2007) Standard practice for dry preparation of soil samples for particle-size analysis and determination of soil constants. ASTM International Standards, vol 85, pp 1-2. https ://doi.org/10.1520/D0421-85R07.2

35. ISO (2009) Soil quality-determination of particle size distribution in mineral soil material-method by sieving and sedimentation. International Standards, vol 2002, p 30

36. ASTM D 4972-13 (2012) Standard test method for $\mathrm{pH}$ of soils. ASTM International, vol 04, pp 1-4. https://doi.org/10.1520/ D6103-04.2

37. G187-05 (2001) Standard test method for measurement of soil resistivity using the two-electrode soil box method. ASTM B Standards, pp 1-5. https://doi.org/10.1520/G0187-05.2

38. Somasundaran P (ed) (2004) Encyclopedia of surface and colloid science, 2004 update supplement. CRC Press, Boca Raton. https ://doi.org/10.1201/9781482299625

39. Nasser MS, James AE (2009) The effect of electrolyte concentration and ph on the flocculation and rheological behaviour of kaolinite suspensions. J Eng Sci Technol 4:430-446
40. Gorakhki MH, Bareither CA (2015) Salinity effects on sedimentation behavior of kaolin, bentonite, and soda ash mine tailings. Appl Clay Sci 114:593-602. https://doi.org/10.1016/j. clay.2015.07.018

41. Sunil BM, Shrihari S, Nayak S (2009) Shear strength characteristics and chemical characteristics of leachate-contaminated lateritic soil. Eng Geol 106:20-25. https://doi.org/10.1016/j.engge 0.2008 .12 .011

42. Yong RN, Ohtsubo M (1987) Interparticle action and rheology of kaolinite-amorphous iron hydroxide (ferrihydrite) complexes. Appl Clay Sci 2:63-81. https://doi.org/10.1016/01691317(87)90014-7

43. Wahba MM, Labib BF, Darwish KHM, Zaghloul MA (2017) Application of some clay minerals to eliminate the hazards of heavy metals in contaminated soils. In: 15th International conference on environmental science and technology, CEST

44. Groenenberg B-J (2018) The chemistry of soils, 3rd edn. By Garrison Sposito. Oxford University Press, 2016. Hardback, pp 272. Price GBP 59.00, EUR 216.00. ISBN 9780190630881. Acta Crystallogr Sect C Struct Chem 74:651-652. https://doi.org/10.1107/ s2053229618003108

45. Goldberg S, Forster HS, Godfrey CL (1996) Molybdenum adsorption on oxides, clay minerals, and soils. Soil Sci Soc Am J 60:425432. https://doi.org/10.2136/sssaj1996.03615995006000020013 $\mathrm{x}$

46. Turer D (2007) Effect of heavy metal and alkali contamination on the swelling properties of kaolinite. Environ Geol 52:421-425. https://doi.org/10.1007/s00254-006-0557-x

47. Assem Al, Nasr-El-Din HA, Fuss T, Shi J, Herskovits R (2017) Mud-acid interactions with sand and clay-based ceramic proppants used in gravel-packed and fractured wells. SPE Prod Oper 32:196-207. https://doi.org/10.2118/175833-PA

48. Carroll-Webb SA, Walther JV (1988) A surface complex reaction model for the $\mathrm{pH}$-dependence of corundum and kaolinite dissolution rates. Geochim Cosmochim Acta 52:2609-2623. https ://doi.org/10.1016/0016-7037(88)90030-0

Publisher's Note Springer Nature remains neutral with regard to jurisdictional claims in published maps and institutional affiliations. 